CORRIGENDA

\title{
Protein kinase CKIIa interacts with the Bcr moiety of Bcr/Abl and mediates proliferation of Bcr/Abl-expressing cells
}

Suparna Mishra, Anja Reichert, Jess Cunnick, Dinithi Senadheera, Bianca Hemmeryckx, Nora Heisterkamp and John Groffen

Oncogene (2004) 23, 6325. doi:10.1038/sj.onc. 1207743

Since the publication of the above paper, the authors have identified an error. In the Acknowledgements section, Dr Lorenzo Pinna should have been thanked for providing the TBB. The authors apologise for this

Correction to: Oncogene (2003) 22, 8255-8262, error and regret any confusion and/or inconvenience it doi:10.1038/sj.onc. 1207156 may have caused.

\section{Immunological and pathobiological roles of fibulin-1 in breast cancer}

Serenella M Pupa, Scott W Argraves, Stefania Forti, Patrizia Casalini, Valeria Berno, Roberto Agresti, Piera Aiello, Annamaria Invernizzi, Paola Baldassari, Waleed Otwal, Roberta Mortarini, Andrea Anichini and Sylvie Ménard

Oncogene (2004) 23, 6325. doi:10.1038/sj.onc. 1207746

Correction to: Oncogene (2004) 23, 2153-2160, doi: 10.1038/sj.onc. 1207323

Published online 22 December 2003.
Since publication of the above manuscript, the authors have identified an error in two of the author names. The correct names are William S Argraves and Waleed O Twal. 